\title{
Transradial angiography procedure approach in with and without radial artery anomalies
}

\author{
Saeed Yazdankhah, Ahmadreza Assareh", Shahla Majeedi, Mehdi Easapour, \\ Mohammad Nourizadeh, Farzaneh Ahmadi, Farzad Daeinejad \\ Cardiovascular Disease Research Center, Joundishapour University, Ahvaz, Iran; \\ *Corresponding Author: Dr.Assareh@gmail.com
}

Received 13 April 2013; revised 14 May 2013; accepted 1 June 2013

Copyright (C) 2013 Saeed Yazdankhah et al. This is an open access article distributed under the Creative Commons Attribution License, which permits unrestricted use, distribution, and reproduction in any medium, provided the original work is properly cited.

\section{ABSTRACT}

Introduction: The transradial coronary angiography has several benefits such as the reducetion in access site complications especially in fully anticoagulated patients. The presence of arterial anomalies in upper limb arteries has an important role in procedural success. Methods: retrograde transarterial sheath injection was done in patients with transradial coronary angiography. Arterial anomalies in the upper limb evaluated. Cannulation time, the time of catheter passage to ascending aorta, and Angiographic time, were also meseared. Results: in 2011, 165 consecutive patients were studied, $116(70.3 \%)$ male, age $56.7 \pm 11.1$ years. With $96.6 \%$ success rate in procedure, totally 59 anomolies were observed in 44 patients $(26.7 \%)$. Radial artery by itself had -25 anomalies $(15.1 \%)$. The most frequent anomaly was abnormal origin of radial artery in 14 patients $(8.5 \%)$ followed by tortuosities in 10 ulnar (6\%). 9 brachial $(5.4 \%), 7$ radial $(4 / 2 \%), 5$ subclavian $(3 \%)$ and 3 brachiocephalic arteries $(1.8 \%)$. There also were 4 loops in ulnar artery $(2.4 \%)$ and one in radial and brachinl arteries (each $0.6 \%)$. Other anomalies include 4 patients $(2.4 \%)$, except cannulation time $(p=0.97)$, there were associations between anomalies and each of other times $(p=0.001)$ and contrast volume $(p=$ 0.009). Anomalies didn't have any effect on procedural success rate and just in one patient with sulclavian loop procedure changed to femoral approach $(p=0.19)$.

Keywords: Transradial Angiography; Radial Anomalies

\section{INTRODUCTION}

Coronary angiography and interventions from the radial artery have gained popularity mainly because of a very low complication rate with immediate postprocedural sheath removal, despite full heparinization and antiplatelet therapy [1]. The transradial approach (TRA) was also preferred by patients when compared to the transfemoral approach [2]. However, this approach has also some limitations, which include definite learning curve, procedural failure rate, and occasional patient discomfort caused by arterial spasm. These last two limitations are seen more frequently with radioulnar loops and extreme arterial tortuosity. Recently, dramatic reduction of pain and spasm has been described with the use of a hydrophilic-coated introducer sheath [3]. The transradial technique is, however, associated with a significant learning curve even for experienced femoral operators [4-6]. Although procedure failures can sometimes be due to radial artery anatomical variations, there are limited data describing such variations [7]. We undertook to establish the frequency of the radial artery anomalies and their relation to procedure outcome in patients undergoing a first transradial coronary procedure.

\section{MATERIALS AND METHODS}

\subsection{Study Population}

This was a prospective study that was performed in Imam Hospital of Iran. A total of 164 consecutive patients undergoing their first transradial coronary procedure were recruited from May 2011 to December 2011. Only patients undergoing diagnostic angiography and coronary intervention were studied. clinical characteristics, procedural information, and clinical outcomes were obtained from the database and confirmed by chart review Patients with a previous transradial procedure were excluded. 


\subsection{Radial Artery Cannulation}

\subsubsection{Transradial Procedure}

Right TRA. After positive evaluation of radioulnar hand arterial arch patency with oximetry and plethysmography test [4], the right arm was placed without constraint in an abducted position with slight wrist overextension [5]. Local skin anesthesia was obtained with 0.2 cc of lidocaine $2 \%$ injected subdermally with a 20 gauge needle. A small $(1 \mathrm{~mm})$ incision was made with No. 11 surgical blade before radial artery was punctured at approximately $2 \mathrm{~cm}$ proximal to the styloid process with either a 20 gauge open needle to obtain a pulsatile blood flow. The artery was cannulated with either a guidewire. A 4 - 6 Fr, hydrophilic sheath was then inserted. The arm was then positioned alongside the patient and an arterial vasodilator (containing $100 \mu \mathrm{g}$ nitroglycerine and 2.5 $5.0 \mathrm{mg}$ of verapamil) given according to local protocols. Heparin (2500 - 5000 iu.) was given either as part of the vasodilator cocktail or in the aortic root.

\subsubsection{Retrograde Radial Arteriography}

Retrograde radial arteriography was performed following administration of the arterial vasodilator to define radial artery anatomy from mid-radius to radio-brachial anastomosis. A solution of $4 \mathrm{ml}$ of contrast mixed with 8 $\mathrm{ml}$ of blood (to dilute the contrast and minimise any discomfort from contrast injection) was injected briskly through the side arm of the sheath with radiographic acquisition at the elbow in an anteroposterior projection. If a high bifurcating radial origin was identified, a further arteriogram was obtained higher up the arm to identify the point of anastomosis to the brachial artery.

\subsubsection{Transradial Coronary Procedures}

Retrograde radial arteriography was performed prior to coronary intubation in all patients. In patients who had a failed transradial puncture, it was at the discretion of the operator to attempt the contralateral radial artery or use the transfemoral approach. The arterial sheath was removed immediately after completion of the transradial procedure and haemostasis achieved using a unilateral radial compression system.

\subsection{Classifications and Definitions}

The site of anomalous origin was determined with reference to the intercondylar line of the humerus, which is a fixed line representing the proximal border of the antecubital fossa.

Bifurcation of the brachial artery proximal to this line is considered a variant pattern. A radial artery loop was defined as the presence of a full $360^{\circ}$ loop of the radial artery distal to the bifurcation of the brachial artery. Extreme radial tortuosity was defined as the presence of a bend of more than $90^{\circ}$ in the contour of the vessel. Anatomical variations that did not fit into these specified categories were grouped together and categorised as "other" anomalies.

Angiographic duration was defined as time interval when coronary cannulation performed until the last image was taken. Procedural success was defined as completion of the planned procedure via the initially selected radial access route. "Access time" was defined as the time interval from administration of local anaesthesia at the arterial puncture site to successful placement of an arterial sheath. "Cannulation time" was defined as the time interval from placement of the arterial sheath to successful acquisition of the first angiographic image. Minor vascular complications were defined as haematoma $<5 \mathrm{~cm}$, vessel dissection without ensuing ischaemia, pseudoaneurysm and localised infection. Major vascular complications were defined as haematoma $>5 \mathrm{~cm}$, any access site complications that required surgical or radiological intervention, $>3 \mathrm{gm} / \mathrm{dl}$ haemoglobin drop due to access site bleeding, bleeding requiring transfusion, limb ischaemia and/or compartment syndrome.

\subsubsection{Data Collection}

Patient demographics, procedural data, and radial arteriography findings with specific details of any anomalies and local vascular complications were collected on a specifically written data management database.

\subsubsection{Statistical Analysis}

Statistical analysis was performed using SPSS 16.0 for Windows (SPSS Inc., Chicago, Illinois, USA). Categorical data were presented as absolute values and percentages whereas continuous data were presented as mean \pm standard deviation. Student's t test was used to compare continuous data as appropriate.

\subsubsection{Categorical Data}

Categorical data were compared using the Chi-Square test with the appropriate degree of freedom. Multivariate regression analysis were used to examine potential correlation between radial artery anomaly and variables such as sex, age, hypertension, diabetes and a $p$ value of less than 0.05 was considered to be statistically significant.

\section{RESULTS}

Baseline patient and procedural data are summarised on Table 1.

A total of 164 patients were studied with mean age $56.7 \pm 11 / 1$ years and $70.3 \%$ male. (Table 2)

Transradial procedural success was $96.6 \%$ with $3.4 \%$ of patients requiring femoral access for procedure completion. 
Table 1. Basic characteristics of patients.

\begin{tabular}{ccc}
\hline & Number & Percent $\%$ \\
\hline Age & $56.7 \pm 11 / 1$ & \\
Male & 116 & $70 / 3$ \\
Smoker & 43 & $26 / 1$ \\
HTN & 74 & $44 / 8$ \\
HLP & 52 & $31 / 5$ \\
DM & 34 & $20 / 6$ \\
Normal coronary & 41 & $27 / 7$ \\
1 Vessel disease & 24 & $16 / 7$ \\
2 Vessel disease & 34 & $22 / 9$ \\
3 Vessel disease & 46 & 31 \\
Left main & 8 & $5 / 4$ \\
More than 1 catheter & 36 & 25 \\
Anomaly & 44 & $26 / 7$ \\
Spasm of radial artery & 33 & $22 / 3$ \\
\hline
\end{tabular}

Table 2. Ages of male and female patients.

\begin{tabular}{cccccc}
\hline & Number & $\begin{array}{c}\text { Minimum } \\
\text { (years) }\end{array}$ & $\begin{array}{c}\text { Maximum } \\
\text { (years) }\end{array}$ & $\begin{array}{c}\text { Mean } \\
\text { (years) }\end{array}$ & $\begin{array}{c}\text { Standard } \\
\text { deviation }\end{array}$ \\
\cline { 2 - 5 } Male & 116 & 30 & 86 & $57 / 2$ & $11 / 7$ \\
Female & 49 & 36 & 75 & $55 / 4$ & $9 / 4$ \\
Total & 165 & 30 & 86 & $56 / 7$ & $11 / 1$ \\
\hline
\end{tabular}

\subsection{Radial Artery Anatomy and Procedural Outcome}

There were 2 cases $(1.4 \%)$ of radial puncture failure. Retrograde radial arteriography was obtained in 164 patients. Anomalies were noted in $44(26.7 \%)$ and there wasn't significant change in age (mean age 59.3 years versus $57.7, \mathrm{p}>0.05$ ) more commonly female (36\% versus $28 \%, p=0.02$ ) with significantly higher procedure failure. Although procedure duration and fluoroscopy time were longer in patients with anomalies, these were not statistically significant.

\subsection{Normal Radial Artery Anatomy}

Normal radial artery anatomy was present in 138 patients $(86.2 \%)$.

Procedure failures were due to subclavian artery loop (1 patient).

\subsection{Radial Anomalies}

A summary of anomaly types and associated failure rates is shown in Figure 1. There were not seen any relation between age and gender and presence of radial artery anomaly.

\subsection{High-Bifurcating Radial Origin}

This was the most frequent radial anomaly (Figure 2) observed in 8 patients with a frequency of $4.8 \%$. The majority of these vessels rejoined the brachial artery at the level of mid or upper humerus. High-bifurcating radial artery was not associated with a high incidence of transradial failure \%).

\subsection{Radial Artery Loop}

A radial artery loop was observed in 1 patient $(0.6 \%)$. These mostly involved the proximal radial artery just below the brachial bifurcation

\subsection{Extreme Radial Artery Tortuosity}

Extreme radial artery tortuosity was observed in 7 patients $(4.2 \%)$. Although these vessels were prone to severe radial artery spasm, the presence of extreme radial tortuosity was not associated with a high procedural failure rate. These had no clinical significance since all cases were completed via the chosen radial access site.

\subsection{Vascular Complications}

No patients had bleeding requiring transfusion or surgical intervention. Access site vascular complications in 3 patients $(2 \%)$ were treated conservatively. These were: large haematoma [2], arterio venous fistula [1], immediate radial artery occlusion [2] and axillary artery dissection [1]. Two patients with large haematoma were successfully treated with customised compression and arm elevation without evidence of compartment syndrome or hand ischaemia. The patient with arteroiovenous fistula also managed conservatively without ischaemic sequelae.

\section{DISCUSSION}

Transradial percutaneous coronary procedures have gained popularity because of reduced access site vascular complications and immediate patient mobilisation. Procedural success has been facilitated through technological enhancements and miniaturisation of equipment.

Reported technical failure for transradial procedures is between $1 \%$ - 5\% [8-11] compatible with our overall figure of $3.4 \%$. There are several reasons leading to failure: inability to puncture, artery spasm and anatomical variations. Whereas incidence of the former are documented [3,9-11], information relating to radial artery anatomical variation is limited. 


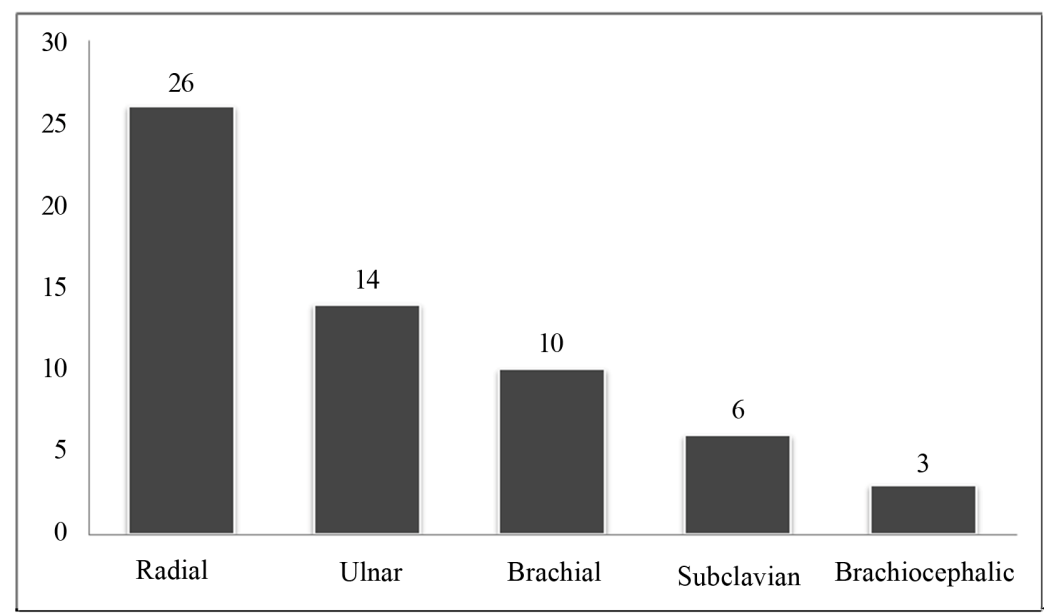

Figure 1. Number of anomalies in each artery.

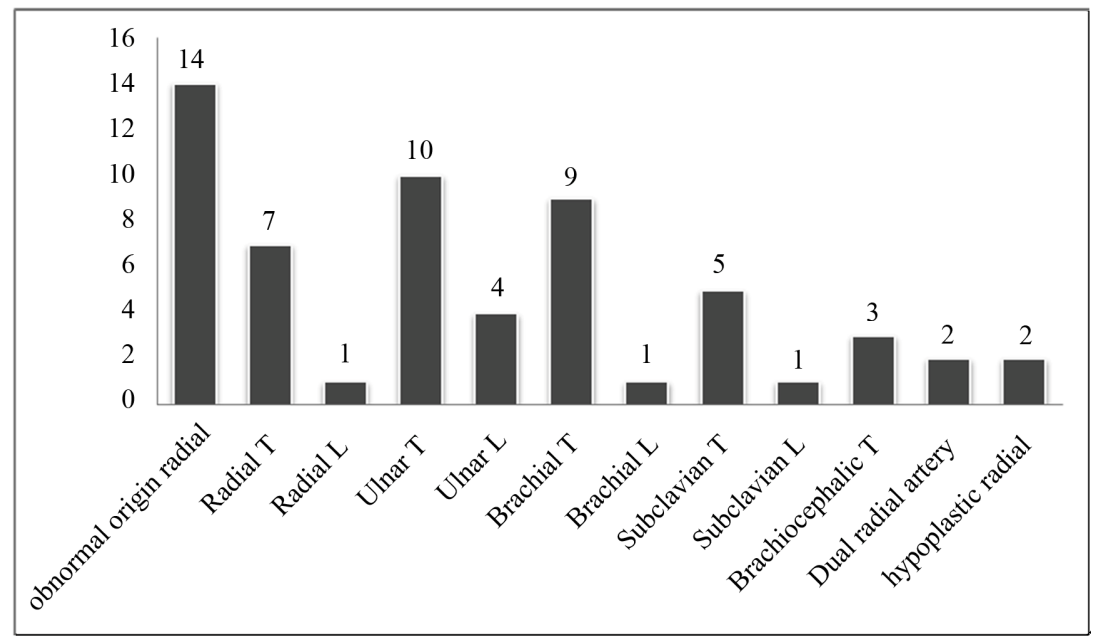

Figure 2. Number of anomalies in each artery. $\mathrm{T}=$ Tortuosity, $\mathrm{L}=$ Loop.

Furthermore, there is a paucity of data on the presence of radial artery anomaly and its relation to procedure failure. Our data defines radial artery anomalies in $26.6 \%$ of patients undergoing a first transradial cardiac procedure. Furthermore, in our study although the total time of procedure in patients with radial anomali prolonged, in contrast to Barbeau study we didn't observe higher procedure failure rates in patients with radial artery anomaly, and of clinical interest, different anomalies were not associated with different failure rates for experienced operators [10].

Autopsy studies of upper limb arterial anatomical variation reported a frequency of between $4 \%$ to $18.5 \%$ $[12,13]$. Using 2-dimensional ultrasonography and colour doppler this figure was 9.6\% [14] whilst arteriogramphy studies reported between $7.4 \%$ to $22.8 \%$ [15-17]. Not only were there wide variations in the occurrence of anomaly, there were also variations in the pattern of anomalies reported, partly due to differences in definitions. The frequency of anatomical variation of $26.6 \%$ was more than average of those studies, however, the small sample size and racial variation may have been contributory.

Radial artery hypoplasia was seen in $4.2 \%$ of patients it was against the study of Yoo [16], and Louvard [18] and Barbeaue. It is also worth noting that in our study against Barbaeue [10] radial artery loop was a separate category and one $(0.6 \%)$ full $360^{\circ}$ loops was seen $[10$, 18].

In our study like Barbuae research the most frequent radial artery anomaly observed is high radial bifurcation with a reported frequency of $8.5 \%$. Yoo et al. reported a radial bifurcation incidence of $2.4 \%$ in 1191 Korean patients [16]. The reported $8.5 \%$ in our study was lower than the $14 \%$ in autopsy studies $[12,15]$. Importantly, our study confirmed that this anomaly did not significantly impact on procedural success. The 0.6 frequency of a full $360^{\circ}$ radial artery loop in our study is the lower than $\cdots$ reported. All loops were accompanied by a recurrent radial artery at the apex of the loop which invariably assumed a 
straight path into the upper arm. The presence of the remnant recurrent radial artery has potential to complicate the crossing and straightening manoeuvre, with a tendency for the wire to selectively "follow" the path of the remnant artery thereby increasing risk of dissection or perforation especially if such anatomy has not been initially defined.

Although loops can often be crossed using either a hydrophilic or an angioplasty wire and then straightened with a 5F JR4 configuration diagnostic catheter, these manoeuvres can induce spasm and pain, making subsequent catheter manipulation and advancement impossible. However, more than half of these were patients with large diameter radial loop anatomy deemed impassable after radial arteriography, and procedures were completed via alternative access sites without attempting to cross the loops. Our $\cdots$ definition for extreme tortuosity differed from other studies with a consequent lower frequency of $2.0 \%$, compared to $3.8 \%, 4.2 \%$ and $5.2 \%$ by Valsecchi et al., Yoo et al. and Yokoyama et al. respectively. Variations in bifurcation anatomy had no influence on procedural outcome.

The acquisition of a radial arteriogram requires only a minimal contrast load, a small amount of additional radiation and trivial extra procedural time (Table 3). This is offset by the provision of important information that aids the operator in planning an optimal procedure.

\section{CONCLUSION}

Radial artery anomalies are relatively common and a cause of transradial procedure prolongation time, but many of anomalies do not cause procidural failure for experienced radial operators. Retrograde radial arteriography helps to delineate underlying anomalies, identify patients with unfavourable anatomy thereby informing the operator to plan a strategy to overcome the anomaly or change access route with the potential to save time and avoid vascular complications. This can be performed with a minimum of contrast and should be considered part of a routine transradial procedure.

Table 3. Variation in time and volume contrast in patients with and without radial artery anomalies.

\begin{tabular}{|c|c|c|c|c|c|c|c|c|}
\hline \multirow[b]{2}{*}{ Anomaly } & \multicolumn{2}{|c|}{ Minimum } & \multicolumn{2}{|c|}{ Maximum } & \multicolumn{2}{|c|}{ Mean } & \multicolumn{2}{|c|}{$\begin{array}{l}\text { Standard } \\
\text { deviation }\end{array}$} \\
\hline & + & - & + & - & + & - & + & - \\
\hline Puncture time & 20 & 17 & 240 & 300 & 70 & 60 & 60 & 50 \\
\hline Catheter time & 10 & 7 & 300 & 180 & 60 & 30 & 75 & 23 \\
\hline Angiographic time & 130 & 100 & 2000 & 2250 & 590 & 315 & 510 & 230 \\
\hline Fluoroscopic time & 60 & 45 & 1500 & 720 & 370 & 180 & 350 & 100 \\
\hline $\begin{array}{l}\text { Volume of } \\
\text { contrast agent }\end{array}$ & 25 & 25 & 120 & 120 & 48 & 38 & 20 & 12 \\
\hline
\end{tabular}

The limit of this study was the small sample size and a further study with larger sample size should be done.

\section{REFERENCES}

[1] Kiemeneij, F., Laarman, G.J., Odekerken, D., Slagboom, T. and van der Wieken, R. (1997) A randomized comparison of percutaneous transluminal coronary angioplasty by the radial, brachial and femoral approaches: The ACCESS study. Journal of the American College of Cardiology, 29, 1269-1275. doi:10.1016/S0735-1097(97)00064-8

[2] Cooper, C.J., El-Shiekh, R.A., Cohen, D.J., et al. (1999) Effect of transradial access on quality of life and cost of cardiac catheterization: A randomized comparison. American Heart Journal, 138, 430-436. doi:10.1016/S0002-8703(99)70143-2

[3] Dery, J.P., Simard, S. and Barbeau, G.R. (2001) Reduction of discomfort at sheath removal during transradial coronary procedures with the use of a hydrophilic-coated sheath. Catheterization and Cardiovascular Interventions, 54, 289-294. doi:10.1002/ccd.1286

[4] Louvard, Y., Lefevre, T. and Morice, M.C. (1997) Radial approach: What about the learning curve? Catheterization and Cardiovascular Diagnosis, 42, 467-468. doi:10.1002/(SICI)1097-0304(199712)42:4<467::AID-C CD30>3.0.CO;2-E

[5] Louvard, Y., Pezzano, M., Scheers, L., Koukoui, F., Marien, C., Benaim, R., et al. (1998) Coronary angiography by a radial artery approach: Feasibility, learning curve. One operator's experience. Archives des Maladies du Coeur et des Vaisseaux, 91, 209-215.

[6] Goldberg, S.L., Renslo, R., Sinow, R. and French, W.J. (1998) Learning curve in the use of the radial artery as vascular access in the performance of percutaneous transluminal coronary angioplasty. Catheterization and Cardiovascular Diagnosis, 44, 147-52. doi:10.1002/(SICI)1097-0304(199806)44:2<147::AID-C $\underline{\mathrm{CD} 5>3.0 . \mathrm{CO} ; 2-6}$

[7] Louvard, Y. and Lefevre, T. (2000) Loops and transradial approach in coronary diagnosis and intervention. Catheterization and Cardiovascular Interventions, 51, 250-252. doi:10.1002/1522-726X(200010)51:2<250::AID-CCD24 $>3.0 . \mathrm{CO} ; 2-0$

[8] Kiemeneij, F., Laarman, G.J., Odekerken, D., Slagboom, T. and van der Wieken, R. (1997) A randomized comparison of percutaneous transluminal coronary angioplasty by the radial, brachial and femoral approaches: The access study. Journal of the American College of Cardiology, 29, 1269-1275. doi:10.1016/S0735-1097(97)00064-8

[9] Ludman, P.F., Stephens, N.G., Harcombe, A., Lowe, M.D., Shapiro, L.M., Schofield, P.M., et al. (1997) Radial versus femoral approach for diagnostic coronary angiography in stable angina pectoris. American Journal of Cardiology, 79, 1239-1241. doi:10.1016/S0002-9149(97)00089-1

[10] Barbeau, G.R. (2003) Radial loop and extreme vessel tortuosity in the transradial approach: Advantage of hydrophilic-coated guidewires and catheters. Catheterization 
and Cardiovascular Interventions, 59, 442-450. doi:10.1002/ccd.10586

[11] Hildick-Smith, D.J., Ludman, P.F., Lowe, M.D., Stephens, N.G., Harcombe, A.A., Walsh, J.T., et al. (1998) Comparison of radial versus brachial approaches for diagnostic coronary angiography when the femoral approach is contraindicated. American Journal of Cardiology, 81, 770772 . doi:10.1016/S0002-9149(97)01013-8doi:10.1007/BF025 $\underline{77379}$

[12] Rodriguez-Niedenfuhr, M., Vazquez, T., Nearn, L., Ferreira, B., Parkin, I. and Sanudo, J.R. (2001) Variations of the arterial pattern in the upper limb revisited: A morphological and statistical study, with a review of the literature. Journal of Anatomy, 199, 547-566. doi:10.1046/j.1469-7580.2001.19950547.x

[13] Rodriguez-Baeza, A., Nebot, J., Ferreira, B., Reina, F., Perez, J., Sanudo, J.R., et al. (1995) An anatomical study and ontogenetic explanation of 23 cases with variations in the main pattern of the human brachio-antebrachial arteries. Journal of Anatomy, 187, 473-479.

[14] Yokoyama, N., Takeshita, S., Ochiai, M., Koyama, Y., Hoshino, S., Isshiki, T., et al. (2000) Anatomic variations of the radial artery in patients undergoing transradial cor- onary intervention. Catheterization and Cardiovascular Interventions, 49, 357-362.

doi:10.1002/(SICI)1522-726X(200004)49:4<357::AID-C CD1>3.0.CO;2-Z

[15] Uglietta, J.P. and Kadir, S. (1989) Arteriographic study of variant arterial anatomy of the upper extremities. CardioVascular and Interventional Radiology, 12, 145-148.

[16] Yoo, B.S., Yoon, J., Ko, J.Y., Kim, J.Y., Lee, S.H., Hwang, S.O., et al. (2005) Anatomical consideration of the radial artery for transradial coronary procedures: Arterial diameter, branching anomaly and vessel tortuosity. International Journal of Cardiology, 101, 421-427. doi:10.1016/j.ijcard.2004.03.061

[17] Valsecchi, O., Vassileva, A., Musumeci, G., Rossini, R., Tespili, M., Guagliumi, G., et al. (2006) Failure of transradial approach during coronary interventions: Anatomic considerations. Catheterization and Cardiovascular Interventions, 67, 870-878. doi:10.1002/ccd.20732

[18] Rodriguez-Niedenfuhr, M., Sanudo, J.R., Vazquez, T., Nearn, L., Logan, B. and Parkin, I. (2000) Anastomosis at the level of the elbow joint connecting the deep, or normal, brachial artery with major arterial variations of the upper limb. Journal of Anatomy, 196, 115-119. doi:10.1017/S0021878299005737 